\title{
A EXPERIÊNCIA DA PESQUISA ETNOGRÁFICA NO CONTEXTO DA PANDEMIA DO NOVO CORONAVÍRUS. OS GRUPOS DE MEMÓRIA E SUA NARRATIVA
}

\author{
THE EXPERIENCE OF ETHNOGRAPHIC RESEARCH IN THE CONTEXT OF THE NEW \\ CORONAVIRUS PANDEMIC. MEMORY GROUPS AND THEIR NARRATIVE
}

\author{
Jonatan da Silva Ribeiro ${ }^{1}$
}

RESUMO: A partir do ano de 2019 o mundo presenciou a pandemia do novo coronavírus, que teve como consequência a morte de milhões de pessoas e a um grande isolamento social, afetando de grande maneira a pesquisa de campo e todas as áreas da vida humana. Durante minha pesquisa para elaborar minha dissertação de mestrado tive de fazer entrevistas com pessoas ligadas a movimentos sociais, que lutavam para a desapropriação, tombamento e transformação da Casa da Morte em lugar de memória, a ferramenta mais utilizada, por conta da pandemia, foi as novas mídias e tecnologias, dando um novo sentido a pesquisa.

Palavras-chave: Pandemia. Movimentos Sociais. Memória

SUMMARY: From 2019 onwards, the world witnessed the pandemic of the new coronavirus, which resulted in the death of millions of people and great social isolation, greatly affecting field research and all areas of human life. During my research to prepare my master's thesis I had to do interviews with people linked to social movements, who were fighting for the expropriation, registration and transformation of Casa da Morte into a place of memory, the most used tool, due to the pandemic, was the new media and technologies, giving a new meaning to research.

Keywords: Pandemic. Social Movements. Memory.

\section{INTRODUÇÃO}

A Casa da Morte, localizada no município de Petrópolis, mais especificamente no bairro Caxambu, foi utilizada durante a década de 1970 como um importante centro clandestino da Ditadura Militar, em que opositores ao regime eram presos, torturados e mortos. Innês Etienne

\footnotetext{
${ }^{1}$ Mestrando em Memória Social pelo Programa de Pós-Graduação da Universidade Federal do Estado do Rio de Janeirojonatan3ı@gmail.com
} 
Romeu foi a única que conseguiu ficar viva para contar a história. Com a promulgação da Lei de Anistia, Innês é solta e em depoimento a Ordem dos Advogados do Brasil conta todas as atrocidades que viveu na chamada Casa da Morte. Ao final da década de 1970 Innês volta a Petrópolis e reconhece a Casa em que ficara presa, por motivos políticos e ideológicos. Ao reconhecer a Casa Innês ganha repercussão nacional, inclusive chegando ao imóvel se encontra com o proprietário, na época o alemão Mário Lodders.

Tal revelação causou enorme repercussão na sociedade brasileira e principalmente petropolitana. $\mathrm{O}$ assunto volta à tona em 2010 com força total, quando vários movimentos sociais de Petrópolis se unem para lutar pela desapropriação e tombamento da Casa da Morte, reivindicando a instauração da Comissão Nacional da Verdade na cidade, para apurar os crimes cometidos durante a Ditadura Militar em Petrópolis.

Esses movimentos conseguem a institucionalização da Comissão Municipal da Verdade em Petrópolis e iniciam muitos atos e manifestações em torno do tema desapropriação e tombamento da Casa da Morte, bem como a criação de um Centro de Memória, Verdade e Justiça. Esses movimentos vão para as ruas e realizam passeatas, vigílias, peças teatrais, atos em frente a Casa da Morte e ganham grande visibilidade na mídia local e nacional.

\section{CONTEXTUALIZAÇÃO TEÓRICA}

Os grupos revelam múltiplas maneiras de organização, diferentes motivações e demandas, assim sua composição pode se estruturar a partir de processos de identificação com discursos de classe, gênero, etnia, raça, religião etc. $O$ campo teórico sobre os movimentos sociais se dá como um campo aberto a imaginação sociológica, trazendo significado de ações coletivas. (MUTZENBERG, 20II).

A trajetória dos movimentos sociais é reconstruída por Mutzenberg (20iI) em três grandes períodos. Os anos 1970 e I980 são entendidos pelo autor como a presença de movimentos sociais, os quais os olhares se voltaram para eles, sendo fortemente caracterizado por movimentos populares e de trabalhadores e já era possível perceber a emergência dos "novos movimentos" (de gênero, étnicos, ambientalistas entre outros). (MUTZENBERG, 20II). 
Conforme análise de Ruth Cardoso (1996), dois momentos caracterizaram esse período: o da.emergência heróica dos movimentos., nos 1970, e o momento da institucionalização dos movimentos nos anos 1980. No contexto autoritário e de luta pela redemocratização, a tônica dos estudos estava na afirmação do caráter espontâneo e autônomo dos movimentos sociais. Nesse momento, eles foram interpretados como protagonistas de uma ruptura com o sistema político tradicional, autoritário e clientelista (CARDOSO, 1996, p. 82).(MUTZENBERG, 2011).

O período entre 1970 e 1980, de acordo com Mutzenberg (2011) foi marcado pela reorganização dos movimentos sociais tradicionais e novos, com uma revitalização do sindicalismo rural e urbano. Novas características expressas, são apontadas pelo autor no que convencionou-se chamar sindicalismo, formação de organismos de apoio a organizações, as ONGS e as diversas mobilizações de distintas instituições da sociedade brasileira. (MUTZENBERG, 20II).

$\mathrm{Na}$ década de 1990, os movimentos sociais tomam novos rumos, passando de um nível reivindicatório de oposição ao Estado para implementação de conquistas, que no caso do Brasil se formalizou na Constituição Federal de 1988, por meio da possibilidade de inserção nas diferentes modalidades de conselhos participativos criados a partir da nova ordem constitucional, tal fato levou os movimentos sociais a uma nova posição. Nesse sentido passou-se a ter a exigência de que os movimentos sociais superassem um nível meramente reivindicativo para um nível operacional propositivo, solicitando novas habilidades para o desempenho de atividades de planejamento, implementação e fiscalização de políticas públicas. (MUTZENBERG, 20II).

Uma classificação aproximativa dessa presença pode ser sintetizada como: a) movimentos
identitários que lutam por direitos sociais, econômicos, políticos e culturais (gênero,
geração, portadores de necessidades especiais, imigrantes, territoriais, étnico-raciais,
religiosos etc.); b) movimentos de lutas por melhorias nas condiçôes de vida e trabalho,
tanto rurais como urbanos (terra, trabalho, equipamentos coletivos, habitação etc.); e c)
movimentos globais ou globalizantes. (Fórum Social Mundial, Via Campesina, Jornada
Ação Global dos Povos etc.). (MUTZENBERG, 2oII).

Mutzenberg mostra que existe uma conformidade entre a heterogeneidade da sociedade civil e a heterogeneidade dos movimentos sociais, que caracteriza um campo plural e dinâmico em que as identidades se redefinem nos processos de articulação. Nesse sentido uma pauta interessante no campo temático dos movimentos sociais no Brasil é a sua relação com o Estado, diante da tradição do Estado forte na formação da sociedade brasileira e frente a experiência recente com o Regime Militar, houve a necessidade de afirmar a sociedade civil em contraposição ao Estado. (MUTZENBERG, 20II). 
Para os movimentos sociais, essa relação com o Poder Público tornou-se ainda mais intrincada e ambígua na medida em que lideranças, oriundas de seus quadros, ou no mínimo comprometidas com as suas demandas, tornaram-se governo em seus diferentes níveis (municipal, estadual e federal). Esse fato levou tanto a um afastamento quanto a uma inserção dos movimentos no âmbito dos governos, ou ainda gerando uma dupla atuação, isto é, manifestações de apoio às administrações públicas e à resistência e mobilização, no sentido de acelerar o cumprimento de demandas postergadas (POLETTO, 2009).

De acordo com Mutzenberg (20II) a apropriação da noção de cidadania pelos movimentos sociais teria sido um instrumento fundamental, os levando a um protagonismo de uma nova cultura política. É importante ressaltar que o crescente recurso de "bloqueio de rua" com o objetivo de dar visibilidade a demandas locais, tem chamado muito atenção nos últimos anos, o autor conclui que a multiplicidade de manifestações coletivas e a diversidade de suas características impossibilita uma definição geral do conceito de movimentos sociais, sendo necessário considerar que os atores sociais têm um papel ativo na construção do significado de movimento social. (MUTZENBERG, 20II).

Everton Picolotto defende que a noção de movimento social não é consensual nas ciências sociais, sendo dividido em uma interpretação clássica e as mais recentes. O autor aponta Karl Marx como o que ficou conhecido como um grande ideólogo dos movimentos revolucionários no século XIX, tendo sua autoridade e prestígio intelectuais na afirmação do modelo clássico de movimento social. (PICOLOTTO, 2007).

De acordo com Picolotto (2007) Marx teve grande contribuição na construção de teorias explicativas dos movimentos sociais e também influência na orientação da prática dos movimentos. Marx teria auxiliado na compreensão de relação entre teorização e ação política dos movimentos sociais, articulando a atividade prática (ação dos movimentos) e a teórica (concepção do movimento), em um conjunto único, dando ênfase para o objeto de transformação social. (PICOLOTTO, 2007).

Assim sendo, o marxismo aplicado ao estudo dos movimentos sociais foi entendido não apenas como uma teoria explicativa, mas como uma teoria que fundamenta a movimentos e a própria ação destes movimentos. (PICOLOTTO.p. 158.2007). 
A abordagem marxista, na concepção de Picolotto (2007), busca identificar nos movimentos "a necessidade de organização da comunidade de interesse de classe; a exigência de uma vanguarda para o movimento; o desenvolvimento de uma consciência de classe e de uma ideologia autônoma, uma proposta e um programa de transformação social”. Sendo esses os principais eixos que compõe os movimentos sociais. (PICOLOTTO, 2007).

Com a crise da abordagem marxista surgiram novas concepções de movimento social, a concepção de Novos Movimentos Sociais, nasce de uma grave crítica ao marxismo ortodoxo a respeito de seu conjunto teórico, que privilegiava a análise das estruturas sociais, em especial a econômica considerada determinante da ação humana. O paradigma dos Novos Movimentos Sociais, com ênfase em analisar os movimentos sociais que surgiram a partir de ig6o, principalmente na Europa, considera a visão marxista limitante, por não levar em conta a expressão da subjetividade dos indivíduos, os conceituando apenas por determinações materiais, subestimando as contribuições culturas e a ação criativa dos sujeitos na formação dos movimentos sociais. (PICOLOTTO, 2007).

Alain Touraine define movimento social como "a ação conflitante de agentes de classes sociais lutando pelo controle do sistema de ação histórica." (1977:336). Assim os movimentos sociais se definem pelo "confronto de interesses opostos para controlar forças de desenvolvimento e do campo da experiência histórica de uma sociedade". (1977:344). Nesse sentido, o autor defende que os movimentos sociais devem ter a função de mediadores entre sujeito e o Estado, os movimentos sociais têm o papel de desenvolverem indivíduos livres e autônomos, por um lado e construírem as mediações necessárias entre Estado e os indivíduos por outro.(PICOLOTTO, 2007).

Touraine (1977) propõe que o conceito de movimento social implica a combinação de três princípios, a saber: um (que é a definição do ator por ele mesmo); um princípio de identidade (o ator identifica um adversário); e um (que é a princípio de oposição princípio de totalidade participação no sistema de ação histórica). Dessa forma, o que caracteriza a existência de um movimento social são os três elementos derivados destes princípios: o ator, e seu adversário o que está em jogo no conflito.(PICOLOTTO.p.161.2007).

Picolotto (2007) em seu trabalho traz a discussão a concepção de Castells sobre movimentos sociais, que seriam "ações coletivas com um determinado propósito cujo resultado, tanto em caso de sucesso como de fracasso transforma os valores e instituições da sociedade" (2002: 20). Alberto 
Melucici entende os movimentos sociais como "sistema de ação que operam num campo sistêmico de possibilidade e limites"(I989:52). (PICOLOTTO, 2007).

A definição de movimento social só é útil se permite pôr em evidência a existência dum tipo muito particular de ação coletiva, aquele tipo pelo qual uma categoria social, sempre particular, questiona uma forma de dominação social, simultaneamente particular e geral, invocando contra ela valores e orientações gerais da sociedade, que ela partilha com seu adversário, para privar este de legitimidade.(2003:113).

Os movimentos sociais seriam uma ação coletiva, na atualidade assumem o papel de agentes centrais da renovação social, sua ação contribui na reflexão sobre a realidade concreta, apontando problemas vivenciados, seja por produzirem novas agendas tanto ao Estado, quanto a sociedade civil. Eles não têm a força de aparato, mas tem a força da palavra, sendo constantemente motivados por interesses opostos entre diversos atores sociais que lutam pelo controle das orientações gerais de uma sociedade, sua formação de movimentos sociais se dão no rompimento por meio de afirmação de identidades primárias (religiosas, étnicas, territoriais, nacionais etc) que resultam na construção de comunidades de resistência, com relações fortes entre os atores. (PICOLOTTO, 2007).

Cada tipo de processo de construção de identidade leva a um resultado distinto na constituição dos movimentos na sociedade: a "identidade legitimadora dá origem a uma, ou seja, um conjunto de organizações e instituições da sociedade civil” reproduzem a identidade que racionaliza as fontes de dominação estrutural; a "identidade resistência, leva à formação de comunidades, [...] dá origem a formas destinada à comunas, ou de resistências coletivas diante de uma opressão que, do contrário, não seria suportável” a produz os quais, conforme definidos por Touraine, não são identidades de projeto sujeitos, meramente indivíduos, são "o ator social coletivo pelo qual os indivíduos atingem o significado holístico em sua experiência”(PICOLOTTO.p.167 2007).

Os movimentos sociais são ações sociais de caráter sócio-político e cultural, que revelam formas distintas dos indivíduos e grupos de se organizar e expressar suas demandas, os movimentos sociais estabelecem processos sociais que criam identidades, transformando-se em fontes de criatividade e inovações socioculturais. Indivíduos que antes estavam dispersos e desorganizados ao se integrarem a grupos para manifestar seus pleitos, passam a compartilhar o sentimento de pertencimento social.(ALMEIDA, CORREAA, 2012).

Até o início do século XX o conceito de movimentos sociais abarcava apenas a organização e a ação dos trabalhadores em sindicatos, ao longo do século, diversas teorias foram desenvolvidas. Passou-se a analisar os movimentos em termos de ciclos evolutivos em que seu surgimento, crescimento e propagação ocorriam por intermédio de um processo de comunicação que abrangia 
contatos, rumores reações circulares, difusão das idéias etc. As insatisfações que geravam as reivindicações eram vistas como respostas as rápidas mudanças sociais.(ALMEIDA, CORREA, 2012).

Javier Lifschitz defende que o termo memória política remete a ideia de que enquanto alguns querem esquecer, outros recusam esse esquecimento. Uma "cultura do silêncio" geralmente se sobrepõe em uma sociedade marcada pela violência, sendo o retorno ao passado uma ocorrência emergente. A memória associada a formação de "comunidades de rememoração, também pode implicar na instauração de comissões de verdade e justiça. Lifschitz mostra que Halbwachs (2006), define a memória social como um fenômeno sociológico, que deve ser distinguido tanto da memória individual como da memória histórica. (LIFSCHITZ, 20I6).

A memória social se constitui a partir de experiências vividas por grupos sociais, enquanto a memória histórica é da ordem do registro textual e produzida a partir do poder. A memória social se articula com a oralidade, a pluralidade e a sociedade civil, em contrapartida a memória histórica se relaciona com a textualidade, a unicidade e o Estado, sendo fixa e generalizante, a memória social está em constante deslocamento. (LIFSCHITZ, 2016).

Os grupos de memória podem se desfazer e também se rearticular. Halbwachs mostra que a memória constituía um tipo de vínculo, uma atração desejante sobre o passado, que nasce em grupos e que remete a grupos embora estes não estejam presentes. Nesse sentido a memória começa a ser pensada como forma de agregação social. Halbwachs notou que a memória social articulava um tipo de vínculo singular porque os laços sociais que esta gerava eram sempre espontâneos e efêmeros. (LIFSCHITZ, 2016).

Os grupos de memória implicam em diferentes pontos de vista, em relação ao passado, se estabelecem de forma espontânea e estão sujeitos a um permanente deslocamento. A memória não é intencional. (LIFSCHITZ, 2016).

A memória política não é uma forma de representação imagética, ela também faz alusão a uma espécie de vínculos intencionais. Para o autor estar em um grupo de memória supõe atos de fala ou ações comunicacionais que vão sendo construídas em uma mesma gramática de lembranças e sentimentos, seriam "Comunidades afetivas", como defende Halbwachs. (LIFSCHITZ, 2016).

A memória política busca intervir no mundo social, confrontando a realidade jurídica, cultural e política, porque aborda narrativas e práticas que somente tomam força quando chegam 
a esfera pública, sendo um tipo de ação estratégica. A finalidade da memória política seria a de chegar e confrontar no espaço público, acontecimentos que estiveram ocultos e visões de justiça. As lutas por memória se articulam com formas de pensar e classificar visões de mundo, sendo um campo estritamente heterogêneo. As políticas de Estado podem facilmente punir, inibir e motivar a eclosão de narrativas. (LIFSCHITZ, 2016).

\section{METODOLOGIA}

A metodologia que decidi seguir foram a pesquisa documental, pesquisa de campo, utilizando-me da História Oral, as observações de campo, no intuito de produzir uma etnografia, e a pesquisa bibliográfica, assim como a Antropologia Digital.

Goldenberg (2002), afirma que ao conhecer, caracterizar, analisar e elaborar sínteses sobre um objeto de pesquisa, o investigador dispõe de diversos instrumentos metodológicos. "o que determina como trabalhar é o problema que se quer trabalhar: só se escolhe o caminho quando se sabe onde se quer chegar. (GOLDENBERG, p-I4, 2002).

Abordando a pesquisa documental, que foi muito útil na elaboração desse trabalho, é interessante comentar que o uso de documentos, de acordo com Cellard, deve ser valorizado e apreciado na pesquisa, pois permite acrescentar a dimensão do tempo a compreensão do social. A análise documental favorece a observação do processo de maturação ou de evolução de indivíduos, grupos, conceitos conhecimentos entre outros. (CELLARD, 2008).

A pesquisa documental é um procedimento que se utiliza de métodos e técnicas para apreensão, compreensão e análise de documentos dos mais variados tipos, tanto a pesquisa bibliográfica, como a pesquisa documental tem o documento como objeto de investigação. $\mathrm{O}$ documento como fonte e pesquisa pode ser escrito e não escrito. (SÁ-SILVA, 2009). Le Goff (1985), trazendo a ideia do uso das fontes para além dos documentos escritos e materiais, faz uma importante reflexão:

(..) quando os documentos escritos faltam à História, ela deve pedir as línguas mortas os seus segredos e, através das suas formas e palavras, adivinhar o pensamento dos homens que as falaram. A história deve perscrutar as fábulas, os mitos, os sonhos da imaginação, todas essas velhas falsidades sob as quais ela deve descobrir alguma coisa de muito real, as crenças humanas. Onde o homem passou e deixou alguma marca de sua vida e inteligência, aí está a História. (apud LE GOFF, 1985, P.219) 
Oliveira (2007), faz uma interessante distinção entre pesquisa bibliográfica e pesquisa documental, para a autora a pesquisa bibliográfica é uma modalidade de estudo e análise de documentos de domínio científico, tais como livros, periódicos, enciclopédias, ensaios críticos, dicionários e artigos científicos, estudando diretamente fontes científicas, sem precisar recorrer a fatos e fenômenos da realidade empírica. (OLIVEIRA, p.69, 2007).

A pesquisa documental é apontada por Oliveira (2007), como a busca de informações em documentos que não receberam nenhum tratamento científico, como relatórios, reportagens de jornais, revistas cartas, filmes, gravações, fotografias entre outras. A pesquisa documental é muito próxima da pesquisa bibliográfica, o que as difere seria a natureza das fontes. Na pesquisa documental o trabalho do pesquisador requer uma análise mais cuidadosa, pois os documentos não passaram por nenhum tratamento científico. (OLIVEIRA, p.29,2007).

As fontes primárias são dados originais, que possuem uma ligação direta com os fatos a serem analisados, é função do pesquisador analisá-las, por fontes secundárias, entende-se a pesquisa de dados de segunda mão, informações que foram trabalhadas por outros estudiosos. (OLIVEIRA, p.69.2007). O historiador dos Anais aponta que "os documentos e os testemunhos só falam quando sabemos interrogá-los" (FEBVRE, 20II, p. 82).

Não é tarefa fácil conceituar a categoria de documento. Cellard (2008), busca recuperar a palavra "documento" como uma declaração escrita, oficialmente reconhecida que serve de prova de um acontecimento, fato ou estado, na escola positivista o documento era sobretudo oficial, escrito. (CELLARD, p.296. 2008).

A partir do século XX, com a Revista Francesa dos Anais, o conceito de documento é ampliado. Tudo o que é vestígio do passado, tudo o que serve de testemunho pode ser considerado como documento ou fonte, pode se tratar de textos escritos, mas também de natureza iconográfica e cinematográfica ou de qualquer outro tipo de testemunho, registro, objetos do cotidiano. Dentro dessas condições é possível defender que até relatórios de entrevistas ou anotações, feitas durante uma observação podem ser caracterizadas como documento. (CELLARD, 2008).

Quanto a ida ao campo, por parte do pesquisador, Clifford Geertz, faz importantes reflexões na questão da prática etnográfica. Geertz entende que praticar a etnografia é estabelecer relações, 
selecionar informantes, transcrever textos, levantar genealogias, mapear campos, manter um diário e assim por diante. Para o autor fazer etnografia é como tentar ler e ler no sentido de construir uma leitura, um manuscrito estranho, desbotado, cheio de elipses, incoerências, emendas suspeitas e comentários tendenciosos. (GEERTZ, 2008).

Nesse sentido, a descrição etnográfica trata, pois, de articular o olhar, o ouvir e a escrita, construindo uma "interpretação densa" dessa experiência, buscando dar conta de algumas de suas estruturas de significado. E a etnografia é a inscrição dessa interpretação de tudo que vemos e ouvimos no campo. A descrição etnográfica é, dessa perspectiva, a apreensão e a inscrição de uma determinada realidade cultural a partir dos olhos e dos ouvidos do antropólogo. (CUNHA, VALPASSOS, p.39. 2012).

Geertz mostra que compreender a cultura de um povo expõe a sua normalidade sem reduzir suas particularidades. A etnografia na concepção do autor é uma descrição densa e os etnógrafos são aqueles que fazem a descrição. A etnografia para Geertz é interpretativa e microcópia. (GEERTZ, 2008).

Lévi-Strauss (1975), numa tentativa semelhante à de Mauss de travar um debate sobre o método de observação e investigação antropológica, destaca que a etnografia consiste na observação e na análise dos grupos humanos em suas particularidades a fim de reconstituir fielmente a vida de cada um deles. O conhecimento dos fatos sociais só é possível a partir de uma investigação concreta e minuciosa dos grupos sociais, contextualizados em seu tempo e espaço, a fim de se alcançar as estruturas mais inconscientes do pensamento humano. Segundo Lévi-Strauss (1975), o inconsciente possui função simbólica, por estar sujeito às leis que estruturam a sociedade e por produzir símbolos que são eficazes por ordenarem a estrutura do pensamento simbólico (GEERTZ, 2008, p.5).

Ainda na questão metodológica, por meio de Ferraz e Porto (2017), é possível defender uma Antropologia Digital, que se torna uma ferramenta essencial no trabalho etnográfico, principalmente no contexto dos novos tempos de pandemia da Covid-19 e isolamento social.

[...] desprezar a condição digital da cultura contemporânea, a qual se alastra em todas as esferas das relações sociais (se apresentando também como campo e/ou objeto de pesquisa) é ignorar as recentes mídias no cotidiano das relações sociais como o fato social da nossa era. E tornar perecíveis os métodos antropológicos tradicionais para certas culturas, por não darem conta de explicar as relações culturais intoxicadas pelas tecnologias nas relações sociais e materiais. Na Antropologia clássica, livros, informantes e percursos terrestres eram tidos como a condição para os contatos preliminares no início da pesquisa, no entanto, na esfera atual das relações sociais em rede, são comumente substituídos por ícones em telas conectadas via online. Portanto, é a partir da entrada nos sites de busca e nas redes sociais, onde se abarcam as referências preliminares das diferentes temáticas do estudo, correspondendo ao lugar onde se inicia o emprego da etnografia. E a internet, como tal portal, pode convergir sobre o caminho da proposta etnográfica tradicional de Mauss (1999:05-07), que está na ação do etnógrafo em observar e classificar os fenômenos sociais, 
pois as diversas formas de olhar, agora em rede digital, que de antemão proporcionam o contato com um universo de possibilidades de estudos. (FERRAZ; PORTO, 2017, p. 6-7).

Nesse sentido é interessante abordar a etnografia digital que Skageby(2013), mostra os seguintes procedimentos de coleta de dados:

b) Observação online - É o primeiro exercício para a coleta de dados, e se dá sob diferentes técnicas, tais como ingressar e observar os grupos de discussões, os arquivos compartilhados, as mensagens publicadas, os perfis de membros das comunidades e páginas estudadas, a procurar destacar as diversas manifestações sociais que emergem deste campo. A combinação das fontes de dados disponíveis nas diferentes plataformas de redes sociais e/ou de busca, é ideal, segundo o autor, para o trabalho dos cientistas que pretendem investigar a atuação dos atores sociais nas diferentes atividades sociais da internet. c) Entrevistas online - No campo online, as entrevistas podem ser sincronizadas ou não. Isso quer dizer que, quando sincronizadas, são feitas em tempo real com câmeras ou com mensagens escritas instantâneas. Cabe acrescentar que a câmera e o áudio garantem a veracidade do entrevistado e trazem outros elementos sobre a atuação e comportamento do ator social em rede, os quais também servem de dados passiveis de análise. Quando não sincronizadas, as entrevistas são as enviadas por e-mail ou mensagens fechadas nas redes sociais e, no caso, são as menos indicadas, pois o tempo do entrevistado para responder pode não ser tão urgente quanto o tempo do pesquisador para

\section{RESULTADOS} desenvolver a sua pesquisa. (FERRAZ; PORTO, 2017, p. 20).

Na terça-feira 12/or/2021 fui a Petrópolis - RJ para visitar a Casa dos 7 Erros e lá me encontrar com Isabel Moreira ${ }^{2}$, uma das integrantes da CMVP, muito bem recebido, fizemos um passeio pelo prédio, fechado devido a pandemia. Nesse tuor Isabel fez um breve comentário sobre as particularidades da Casa dos 7 erros e sua importância histórica, arquitetônica, social e cultural.

Sentamos em uma mesa gigante, antiga e bem trabalhada, ao silêncio da mansão iniciamos a gravação. Isabel dá início a conversa explicando como foi convidada para integrar a CMVP, ela lembra que tinha uma pesquisa particular sobre a presença de nazistas na cidade, frisa que Petrópolis foi a capital do nazismo no Brasil e um terreno de extrema direita, facilitando a implantação da Casa da Morte no município, já com uma forte ideologia predominante.

Isabel faz um levantamento em jornais da época para compreender a Ditadura Militar na cidade e descobre que a Casa da Morte pertenceu a um nazista, assim ela faz associação a uma certa continuidade do pensamento nazista na cidade por meio da Casa da Morte. Diz que Mário Lodders, antigo proprietário do imóvel, era comprovadamente um espião nazista e que existiam comunicações por rádios transmissores que faziam mensagens para a Alemanha nazista na Casa

\footnotetext{
${ }^{2}$ Ao longo do texto foram utilizados nomes fictícios em respeito as pessoas entrevistadas.
} 
da Morte, sendo o fato de ela ter virado a Casa da Morte muito significativo para o uso que ela já teve em seu passado.

Isabel mostra que o objetivo da CMVP era desapropriar a Casa, e lembra do embate com o atual proprietário do imóvel. A entrevistada concebe a CMVP como uma herdeira dos movimentos sociais que lutaram na Ditadura Militar e que a instituição sempre teve o desejo de transformar a Casa em Centro de Memória, porém ressalta que não houve interesse do poder público de investir, estando o discurso da cidade imperial o tempo todo sobrepondo-se.

Para a membro da CMVP a Casa não foi comprada sem o proprietário atual saber, por conta de seu histórico pesado. Existe uma restrição do tema ao meio acadêmico e ausência de comunicação a população, o assunto ainda não chegou bem as pessoas, no entendimento de Isabel.. Por parte do poder público existe um silenciamento a respeito do assunto. A Casa confirmou para Isabel idéias que ela já possuía e um medo de que essas pessoas ainda estão por aí e continuam com seus pensamentos, podendo a Ditadura Militar voltar a qualquer momento.

A Casa da Morte tem uma importância a nível nacional, ela é importante para o Brasil inteiro. Ela confirma que a repressão e a tortura existiram no Brasil. Nosso objetivo sempre foi desapropriar e transformar a casa em Centro de Memória. Ela cumpre uma função social muito importante de que aquilo não deve se repetir, esse imóvel tem tamanha importância para a consolidação da democracia no país. ${ }^{3}$

Terminando a conversa, saí da Casa dos 7 Erros e fui me encontrar com Raniela Machado, em um intervalo de uma hora. Raniela também foi uma importante militante na luta pela desapropriação e tombamento da Casa da Morte. Juntos decidimos ir visitar o imóvel.

Ao chegar na rua observamos uma cancela, câmeras de segurança enormes por todo lado e placas com indicativos de área monitorada 24 horas, aparatos protetivos que até o começo das lutas dos movimentos sociais em prol da desapropriação, tombamento e criação de um Centro de Memória, não existiam. Abandonamos o carro e seguimos a pé pela rua que dá acesso à Casa da Morte. Uma rua extremamente deserta, e com belas casas, de fino acabamento, se caracterizando por frondosas árvores, altas um bairro um tanto afastado, ideal para prática de torturas na década de 1970.

Subindo o morro para a Casa nesse momento meu coração dispara e Raniela que estava comigo e o motorista que nos levou também disseram sentir o mesmo, um sentimento de medo,

\footnotetext{
${ }^{3}$ Trecho de entrevista cedida a mim por Isabel Moreira (nome fictício) em I2 de janeiro de 202r. Petrópolis.
} 
dúvida, pavor e condolências dominaram meu peito, chegando na Casa tiramos inúmeras fotos. Raniela sugere que toquemos o interfone, a pergunta me deixou perplexo, porém não resisti a sugestão e fui em frente. Um imóvel fechado e restrito com portões bem intimidadores, ouvi uma voz grossa e de poucos amigos atendendo e aos berros questionando: "Quem é? O que você quer? Estou muito ocupado!" Se quiser falar comigo deixe seu telefone e e-mail por baixo do portão que entro em contato com você. Não aguentei meus impulsos e adiantei o assunto, mesmo sem poder olhar face a face. Quis saber das memórias que o proprietário tinha construído no imóvel, repeti alguns trechos de seu depoimento e deixei bem claro que eu não estava ali procurando o certo ou o errado e sim tentando entender a história. O proprietário diz não haver contundência no relatório final da CMVP e que os ditos de Innês eram duvidosos, a voz foi ficando cada vez mais longe e sem ao menos se despedir desapareceu. Descemos o morro um tanto impressionados e assustados, diga-se de passagem, olhando o tempo todo para trás.

Nos dirigimos para a escadaria do Centro Cultural de Petrópolis e iniciei a gravação da conversa com Raniela. A deixei totalmente a vontade para falar um pouco de sua visão sobre a Ditadura Militar, a Casa da Morte e seu interesse por ela e sua ativa atuação nos movimentos sociais. Raniela ficou um tempo lecionando a disciplina História, Geografia e Turismo de Petrópolis (HGTP), ela fala de uma deficiência muito grande no currículo em relação ao Brasil Republicano e um esforço em contar a Petrópolis Imperial. Ressalta ter sido em Petrópolis um dos maiores centros de tortura da Ditadura Militar.

O que despertou interesse por saber mais da Casa da Morte, foi sua participação no movimento de desapropriação do imóvel. Raniela lembra que todo ano na ata do Golpe Militar, faziam vários movimentos, situações que lembrassem a Casa da Morte, vigílias, atos simbólicos em praças e caminhadas até a Casa da Morte. Raniela acredita que o movimento já esteve melhor articulado e que agora não está, até mesmo pelo contexto atual da extrema direita no poder.

Na visão de Raniela a pauta da Casa da Morte é de grande importância para as novas gerações poderem conhecer o que ocorreu ali e que a cidade tende a ganhar com a criação de um Centro de Memória, Verdade e Justiça. A política do esquecimento deve ser combatida.

Mesmo sendo de propriedade privada, Raniela acredita que a Casa um dia foi usada com fins de utilidade pública, não se pode desconsiderar a memória de Renato e sim talvez ganhá-lo 
para a idéia. A vida privada de Renato em algum momento acabou se confundindo com a história de Petrópolis, no pensamento de Raniela.

Raniela finaliza a conversa dizendo que a Casa da Morte para ela extrapola a noção do individual, é um objeto da vida pública que representa a resistência, envolvendo questões coletivas e um compromisso coletivo.

A Casa da Morte representa a vida pública das pessoas, ela extrapola o individual, deixou de ser uma questão privada. A Casa da Morte é sinal de resistência, uma resistência ativa, as pessoas estavam ali por questões coletivas, brigaram e sofreram por nós. A Casa da Morte é isso: resistência, eles deram a vida deles, é compromisso nossa essa luta. ${ }^{4}$

No dia 14 de janeiro a partir das I4:0o horas iniciei a gravação com o cineasta Peterson Freitas, que foi selecionado por meio de um edital promovido pela Prefeitura de Petrópolis, para produzir um documentário que tivesse como tema a Casa da Morte e o depoimento de Innês.

Peterson diz que a construção do documentário foi um marco em sua vida, a partir desse momento ele se aprofundou mais nos desdobramentos do Regime Militar, entendendo-o como processo de um país construído em cima da violência de Estado. Peterson ressalta a importância da Casa da Morte e que ela deve ser tema nas escolas, em um contexto do Governo Jair Bolsonaro, que nega as torturas durante a Ditadura das Forças Armadas, é necessário um debate maior na Educação.

Peterson começa pesquisar o que aconteceu na Casa da Morte e sobre Innês, seguindo esse caminho ele inicia uma entrevista a pessoas que estavam na luta para a desapropriação do imóvel. Peterson diz que após a elaboração de seu documentário passou a enxergar a necessidade de a Casa da Morte ser transformada em um Centro de Memória, Verdade e Justiça.

Para ele o valor da Casa é bem maior que qualquer outra memória contrária, e que inclusive serviu para alertá-lo, mostrando que Petrópolis e sua história vão muito além da colonização alemã, do Império e uma cidade de veraneio, infelizmente o governo não trabalha contra, mas também não luta a favor do tombamento e desapropriação da Casa da Morte.

O valor que a Casa tem para o país, para os movimentos sociais, para Petrópolis é enorme, maior que para o proprietário. O que aconteceu ali é muito relevante e já foi provado de várias formas. A Casa da Morte me alertou para o fato de que a história petropolitana é muito maior que a história da colonização alemã ou a história da família imperials

\footnotetext{
${ }^{4}$ Trecho de entrevista cedida a mim por Raniela Machado. Em I2 de janeiro de 2021. Petrópolis.

${ }^{5}$ Trecho de entrevista cedida a mim por Peterson Freitas. Em I4 de fevereiro de 202I. Petrópolis. 
Gláucio Monteiro, membro da CMVP, também foi um dos entrevistados. Ele inicia sua fala salientando o sentido político, econômico e social da Ditadura Militar no Brasil, sendo consequência de um grande passo da burguesia, enriquecendo muitos empresários, vendo o golpe como um caráter de classe.

A Casa da Morte entrou na vida de Gláucio por meio das pesquisas da CMPV, sendo ele um dos convidados para atuar na instituição, Gláucio destaca que mesmo tendo um caráter mais formal, a CMVP sempre teve características de um movimento social e busca por envolver ampla participação da sociedade. Ele revela que com o contexto de ascensão da direita extrema, acabou sofrendo alguns ataques.

Para Gláucio existe o mito de uma cidade européia, colonizada por alemães, com a presença da família imperial, sede da monarquia, sendo uma imagem vendida. Ele acredita ser a Casa da Morte, um direito coletivo e uma reparação, um reconhecimento com importância nacional e internacional, uma luta por Direitos Humanos, direito a vida, contra a tortura, envolvendo toda a sociedade brasileira.

Gláucio percebe entre os grupos disputas a respeito da transformação em Centro de Memória em como será feito, como será o memorial entre outras. Sendo necessário todo um processo democrático nas decisões.

Ao término da entrevista Gláucio diz que a Casa da Morte despertou um sentido de admiração muito grande pelas pessoas que fizeram um enfrentamento do regime e defende que a Casa assume um papel pedagógico e uma denúncia da violência de Estado.

Eu vejo a Casa da Morte como um exemplo, um lugar com sentido pedagógico para mostrar a luta contra a Ditadura Militar, para mostrar o que é a violência política. A Casa da Morte ela tem uma importância no sentido de alertar e denunciar a violência do Estado de maneira geral na história do Brasil. E essa violência não termina, ela continua até hoje e a Casa da Morte vem para mostra tudo isso. ${ }^{6}$

Tive também uma conversa curta, devido ao tempo com uma representante do CDDH, que tinha uma reunião marcada e não pôde falar e me atender por muito tempo. Vera Lobão disse em poucas palavras que para ela a Ditadura Militar foi uma imposição de governo. Mesmo sendo

\footnotetext{
${ }^{6}$ Trecho de entrevista cedida a mim por Gláucio Monteiro. Em o9 de janeiro de 2021. Petrópolis.
} 
nascida e criada em Petrópolis só ficou sabendo da Casa da Morte em 2009, por meio de um encontro sobre debates a respeito da Ditadura.

Uma fala interessante de Vera foi sobre seu encontro como o proprietário do imóvel no Ministério Público, ela disse que Renato confessou já estar saturado com a história toda e que por uma quantia justa abriria mão do imóvel. Vera também em poucas palavras comenta o conservadorismo da cidade e que os movimentos sociais tem sim muitas disputas em relação aos seus objetivos.

A Casa da Morte mudou a concepção de Vera ao perceber as crueldades praticadas pelo poder público e que esses abusos aos Direitos Humanos ainda são presentes.

O CEFET7 é uma importante instituição respeitada na cidade de Petrópolis, e tive a oportunidade de conversar com uma de suas representantes que foi ativa na luta pela desapropriação da Casa da Morte, Felícia Lira, a primeira anfitriã da "Semana de Memória, Verdade e Justiça", foi quem permitiu que o CEFET sediasse esse evento.

Ao decorrer da luta Felícia foi conhecendo as propostas e afirma ser um tema polêmico e com muitas tentativas de silenciamento e apagamento de memórias da Ditadura Militar e da Casa da Morte, trazendo uma certa dificuldade de discussão. "Fala-se muito pouco ainda", de acordo com Felícia Lira.

Existe para Felícia um esquecimento da Petrópolis Republicana e uma parada na Petrópolis Imperial. A disputa entre os vários grupos na luta pela desapropriação e tombamento da Casa da Morte foi um dos motivos dela não querer participar de nenhum deles oficialmente, mas ela tem afinidade com todos e os recebeu muito bem no CEFET.

A Casa da Morte na vida de Felícia veio como um impacto em sua memória pessoal, ela afirma ter vindo de uma família extremamente conservadora, tradicional de direita, sendo petropolitana confessa ver a Casa da Morte como uma casa acoitada, porque não é pública. Os militares têm ainda muita força na cidade, confirma a entrevistada.

A Casa da Morte teve um grande impacto na minha memória pessoal, eu venho de uma família muito conservadora, muito tradicional, muito de direita. Sou petropolitana e estudo as memórias de Petrópolis e sei a força e o impacto que é você ter uma Casa da Morte na Cidade Imperial, ninguém quer essa imagem para a cidade, a Casa existiu é

\footnotetext{
${ }^{7}$ Centro Federal de Educação Tecnológica do Rio de Janeiro.
} 
verídico, é provado, é muito pesado e próximo de todos nós com muitos significados e pessoas envolvidas no meio de uma cidade totalmente tradicional ${ }^{8}$

Diogo Graça, uma das figuras centrais na luta pela desapropriação, líder e fundador do CPL, mesmo estando morando em outra cidade, fez questão de me ceder uma entrevista, por ferramentas virtuais.

Diogo começa falando de sua primeira experiência na adolescência, em relação ao tema Ditadura Militar, por meio da leitura de variados livros ele descobre que os Estados Unidos da América tiveram participação no golpe e consolidação do regime militar no Brasil. Diogo chorava ao ler "Brasil Nunca Mais" e se aproximava cada vez mais da esquerda política.

Diogo diz que com 13 anos de idade participou de sua primeira manifestação de protesto. Em 2orr funda o CPL, organização que buscava uma pauta que fosse relevante para a cidade e também com importância nacional, que não privilegia-se a Petrópolis Imperial, mas que fosse além disso. Mostrar que a memória da resistência em Petrópolis foi um dos objetivos do grupo, assim tomam para si a luta de desapropriação da Casa da Morte de Petrópolis, que já tinha sido lançada pouco antes pelo CDDH.

O movimento social, liderado por Diogo dá início a uma diversidade de ações em prol da desapropriação e tombamento da Casa da Morte, bancas de rua de esclarecimento, coleta de assinaturas e presença nas atividades que envolviam a questão da Casa da Morte foram desenvolvidas pelo grupo.

Diogo lembra que com articulações feitas pela esquerda foi instaurada na cidade a Comissão da Verdade, com a primeira desapropriação da Casa o processo não andou muito, por conta da falta de verba, perdeu-se ainda um dinheiro na quantia de 600 mil reais posta a disposição pela Câmara dos Deputados Federais. Diogo acredita que houve uma certa incompetência do poder público no processo, Dilma Rousseff, por exemplo cita Beto, que foi torturado e morto na Casa da Morte, porém a presidenta não apresentou boa vontade em ajudar no processo da Casa da Morte.

Muitas palestras foram realizadas pelo grupo em escolas. A idéia de tombamento nasce com o objetivo de registrar historiograficamente e oficialmente a Casa em nível de patrimônio.

\footnotetext{
${ }^{8}$ Trecho de entrevista cedida a mim por Felícia Lira em 16 de janeiro de 2021. Petrópolis.
} 
Diogo fala das muitas disputas que ele observa na cidade, entre os grupos e com o proprietário, sendo a causa do tombamento alvo de muitas resistências, para ele o proprietário do imóvel não é um inimigo, porém a casa tem um caráter coletivo e que são muito fortes as memórias das pessoas que morreram e resistiram a tortura, a Casa não será tomada, mas haverá uma recompensação para o proprietário.

Diogo vê como normais e necessárias as divergências em relação a desapropriação e que será feito depois ainda não é o mais importante e sim tombar e desapropriar. O papel fundamental do movimento social é pressionar.

Termino nossa conversa perguntando a Diogo qual o significado da Casa da Morte para ele, Diogo suspira bem fundo e diz ser uma pergunta difícil. A Casa da Morte foi um ponto de encontro em vários aspectos de sua vida. A Casa da Morte foi para Diogo uma maneira de projetar seus desejos e convicções na militância, um encontro do seu eu pessoal. Sendo a Casa impregnada de um coletivo muito forte.

A Casa da Morte é um ponto de encontro em vários aspectos da minha vida, uma forma de projetar minha militância e expor minhas convicções, tem sido um momento importante da minha vida me dedicar a ela. Começamos no banco de uma praça e hoje estamos em dimensão internacional, isso é gratificante ${ }^{9}$

\section{CONCLUSÕES}

O cenário político, cultural, social e também da pesquisa mudou abruptamente com a chegada sem precedentes do novo coronavírus, fazendo com que a prática do pesquisador tivesse que ser repensada, nesse sentido novas maneiras de enxergar os resultados são notórias.

A partir de 2010 com a luta dos movimentos sociais para a desapropriação e tombamento do imóvel intensifica-se a construção de memórias em torno da Casa da Morte, muitos fenômenos podem ser levados em consideração, como à vontade de memória, o desejo de lembrar e preservar essa memória que resistiu durante a Ditadura Militar e essa criação de grupos na luta pela instituição de um Centro de Memória, Verdade e Justiça, atestam a grande necessidade de se lembrar discutida por Hyssen (2014) na contemporaneidade.

Quando esses grupos vão para a frente da Casa da Morte, buscando a legitimação de uma memória e a necessidade da transformação da Casa em museu, eles mostram que a memória é capaz de resistir a tortura, ao tempo e de atravessar gerações. Esses movimentos sofrem embates

\footnotetext{
${ }^{9}$ Trecho de entrevista cedida a mim, por Diogo Graça, líder do CPL. Em 23 de janeiro de 2021.
} 
com o proprietário do imóvel que não acredita que a Comissão Municipal da Verdade de Petrópolis tenha levantado um trabalho verídico, Renato Firmento de Noronha nesse sentido, traz uma reflexão de uma política de esquecimento e apagamento de memórias, bem como uma tentativa de silenciamento, defendendo a ideia de uma propriedade privada, em que ele comprou, ele pagou, ele financiou, sem saber de seu passado tenebroso. Nessa propriedade Renato afirma também ter constituído memórias, o que pode ser visto no processo enviado por ele, trazendo mais uma complexidade nas memórias em torno da Casa da Morte de Petrópolis. Cheia de complexidades a Casa da Morte e os atores envolvidos em sua narrativa se tornou palco de grandes desejos, expectativas, disputas, divisões, ideologias, políticas, sentimentos, deslocamentos, agrupamentos e divisões que levam a Casa da Morte a abrigar uma vasta complexidade em suas memórias.

\section{REFERÊNCIAS BIBLIOGRÁFICAS}

ABREU, Regina. Museus no contemporâneo: entre o espetáculo e o fórum.In:Loures Oliveira, A.P.P. e Monteiro Oliveira, L. (org.) Sendas da Museologia.Ouro Preto, UFOP. 2012.

BARETTA, Jocyane Ricelly. A importância da Materialidade dos Centros Clandestinos de

Detenção e Tortura para contar histórias da Ditadura no Brasil.Aedos, Porto Alegre, v. 9, n. 2I, p. I09-I3I, Dez. 2017 BELLOTO, Heloísa Liberalli. Arquivos Permanentes. Tratamento do documental. RJ: FGV,2006

BRASIL. Comissão Nacional da Verdade: volume I. 2014.COMISSÃO NACIONAL DA VERDADE. Apresentação sobre torturadores e carcereiros identificados por Inês Etienne Romeu ante a Comissão Nacional da Verdade. Acesso em 15/03/2014. Disponível em:

http://www.cnv.gov.br/images/pdf/petropolis/torturadores_carcereiros.

Pdf $>$ CHUVA, Marcia. "Intelectuais e Estado: disputas em torno da noção de patrimônio nacional" in: ANAIS DO MUSEU HISTÓRICO NACIONAL. Vol. 37 (2005), pp. 41-5I.

FILHO, Manuel Ferreira Lima. Cidadania Patrimonial. Revista Anthropológicas. p-134-155.2015.

FOUCAULT, M. “Nietzsche, a genealogia e a história”. In: MACHADO, R. (Org.). Microfísica do poder. Rio de Janeiro: Graal, 1984, p.15-37. 
HALBWACHS, Maurice. A memória coletiva. São Paulo: Centauro, 2004 JELIN, E. 2002. Los trabajos de la memória. Madrid: Siglo XXI.LE GOFF, J. 1994. História e memória. 3. ed., Campinas, SP: Ed. Unicamp.

POLLAK, Michael. A gestão do indizível; WebMosaica Revista do Instituto Judaico Marc Chagall v.2.n.I, p.9-49, 2010. 